Bol. Acad. peru. leng. 51. 2011 (245-249)

\title{
CARLOS E. ZAVALETA $†$
}

Antonio González Montes

Universidad Nacional Mayor de San Marcos

Fecha de recepción:

Fecha de aceptación:
$27 / 06 / 2011$

$30 / 06 / 2011$

En un ciclo vital que abarcó gran parte del siglo XX y la primera década del XXI, Carlos E. Zavaleta (1928-2011) desarrolló una vasta, variada y valiosa obra escrita que, por sus propios méritos ocupa un sitial importante en el campo de las letras peruanas contemporáneas. Llegó a completar más de seis décadas efectivas de producción literaria, pues en 1928, a sus veinte años, publicó su novela El cínico y prácticamente hasta el final de sus días terrenales siguió con el mismo entusiasmo y tesón por dar a conocer sus últimos trabajos.

Existe una correspondencia admirable entre el transcurrir de su existencia y el sentido de su obra literaria. Nació en el departamento de Ancash y en sus primeros años alternó la visión del mar de Chimbote con el contacto directo con la agreste geografía serrana de Corongo, Sihuas, Caraz y de muchos otros lugares en los que vivió y fue completando su formación educativa y literaria. También es digno de resaltar que desde muy joven supo cultivar el dominio de la prosa en lengua española, a la vez que se iniciaba en el aprendizaje y perfeccionamiento del idioma inglés, lo cual le abrió las puertas de otro mundo y de otra cultura. 
Después de un fugaz paso por las aulas de la Facultad de Medicina de la Universidad de San Marcos, experiencia evocada en su novela Un joven, una sombra (1993), Zavaleta optó resuelta y definitivamente por el mundo de las letras. Su primer hogar institucional fue la Facultad de Letras sanmarquina, donde conoció a Raúl Porras, Estuardo Núñez y a otros grandes maestros, a la vez que tomó contacto con sus compañeros generacionales, a quienes se unió para realizar una fructífera labor en el campo académico y en el creativo. Para completar su formación universitaria y ensanchar su visión del mundo viajó muy joven a los Estados Unidos de Norteamérica y allí reforzó su bagaje creativo con la relectura de algunos escritores norteamericanos que él ya conocía desde antes de su viaje y que había difundido entre sus pares nacionales, como lo han reconocido varios de ellos y lo ha ratificado la crítica nacional y extranjera al estudiar el proceso de modernización verificado en el campo de la narrativa (cuento y novela), y en el cual le tocó al creador ancashino un rol protagónico.

Luego de haber culminado sus estudios universitarios y de haber obtenido los más altos grados académicos en su alma máter, y en las instituciones extranjeras donde estuvo becado, retornó al Perú para reiniciar su proficua tarea en los más diferentes campos del quehacer cultural. Siguió publicando libros, creó, dirigió y colaboró con revistas; y no dejó la cátedra universitaria ni el ejercicio constante del periodismo cultural. Gran organizador y animador del mundo de las letras, fue convocado para trabajar como agregado cultural de las embajadas peruanas en diferentes países. Por ello, durante varios años se mantuvo alejado del Perú, pues se encontraba desarrollando activa labor de difusión de la cultura nacional en México, Bolivia, Inglaterra, España.

En la segunda mitad de los ochenta regresó al Perú y desde entonces hasta su deceso ocurrido en el emblemático mes de abril del 2011 desplegó una incansable y productiva tarea intelectual que lo llevó a ampliar las fronteras de su escritura. De hecho, por el volumen de sus publicaciones, es uno de los autores peruanos de más amplia y variada obra, la cual cubre gran parte del campo de las letras. Salvo la creación poética, incursionó en las más diferentes áreas de la prosa narrativa, ensayística, periodística, 
crítica y reflexiva. Y en ese amplio abanico temático que abarcó, ocupó un lugar preferente la figura del inmortal novelista español Miguel de Cervantes.

Si revisamos los géneros y subgéneros del amplio arte literario, comprobaremos que Carlos Eduardo destaca en todos ellos y ha logrado construir un universo escrito verdaderamente original, digno de ser frecuentado. Por ejemplo, en el terreno del cuento, el escritor ancashino ha publicado centenares de relatos reunidos en decenas de libros editados en el Perú y en muchos otros países del mundo, lo cual es un índice de su importancia nacional e internacional. Como miembro ilustre de la generación de los 50 (junto con Ribeyro, Congrains, Vargas Vicuña, Durand y otros) Zavaleta encabezó la renovación y modernización narrativa más radical del siglo pasado, y con ello hizo posible que Joyce, Faulkner, Hemingway, Eliot, Pound y otros grandes creadores contemporáneos influyeran en los escritores más jóvenes, entre los cuales se cuenta Mario Vargas Llosa, Premio Nobel de Literatura 2010, quien ha reconocido el gran rol de pionero que le cupo a Carlos Eduardo, como en su momento también lo hizo Alfredo Bryce. Y es consenso que los dos más grandes cuentistas de la generación de los 50 , vigentes hasta hoy y durante mucho tiempo más, son Zavaleta y Ribeyro, con la diferencia de que el universo cuentístico del primero siguió ampliándose, pues sus denominados Cuentos completos, editados en 1997, al poco tiempo devinieron incompletos. Ese año, nuestro autor alcanzó la proeza de publicar nada menos que siete libros.

En el campo de la novela, especie mayor de la narrativa, nuestro escritor ha logrado plasmar un nutrido grupo de ficciones que recrean interesantes historias ambientadas no solo en pequeños poblados de los andes (como ocurre con Los Ingar-1955), sino en vastos espacios rurales y urbanos que incluso desbordan las fronteras de lo nacional y tienen como escenario ciudades de países americanos y europeos. Pero en todos estos libros, el Perú como referente de los sucesos ficticios destaca con nitidez, porque la estética del autor es realista y sus novelas revelan aspectos esenciales de la idiosincrasia nacional. Por ello debemos leer y releer sus novelas, en especial las últimas, porque son amplias, ambiciosas y están 
enriquecidas con la sabiduría vital y artística de un gran narrador. Entre ellas figuran: El precio de la aurora, Pálido pero sereno, Viaje hacia una flor, Con boleto de vuelta.

Es importante agregar que en el vasto espacio textual de la novelística, Carlos Eduardo ha dado a conocer varias novelas cortas. Es verdad que sus dos primeras, El cínico y Los Íngar, también lo eran; sin embargo, algunas décadas después retomó e incrementó el número de sus novelas cortas, de las cuales recomendamos: Invisible carne herida, El cordero y su piel de lobo, El miembro insomne del jurado, La esquina de Torre Tagle. En todas ellas, el escritor vuelca su conocimiento de la psicología de los personajes y una visión de la vida en la que están presentes el humor, la ironía.

En fin, es una tarea ímproba la de tratar de ofrecer un recuento completo de los libros que publicó Zavaleta. Quizá para hacer justicia y rendir tributo a su inmensa obra escrita convenga mencionar algunos de sus últimos volúmenes y que son parte de su inagotable labor como hombre de letras que gozaba con la creación de nuevas contribuciones que enriquecían su producción y son, a la vez, un verdadero regalo para sus lectores. En su faceta de ensayista, investigador, crítico literario y de antólogo, Carlos Eduardo ha plasmado obras de una gran calidad en su contenido y de brillantez y galanura en su estilo, como buen discípulo de ese gran escritor que es Raúl Porras Barrenechea, sobre el cual ha escrito un luminoso ensayo denominado, precisamente, "Raúl Porras escritor". Pues bien, algunos de los volúmenes memorables son, por ejemplo, El gozo de las letras, imprescindible y magna obra ensayística en tres tomos, y en la cual se pasa revista a una infinidad de tópicos de las letras peruanas, latinoamericanas y mundiales. Por ello, recomendamos vivamente la lectura permanente de este volumen pues es una suerte de amable enciclopedia de gran ayuda para los especialistas y los lectores que simplemente quieren aprender algo valioso pero de modo entretenido y ameno.

Para concluir, citamos tres libros más -no son los únicos que editó en los últimos años- en los que Zavaleta hace gala de otra de sus múltiples facetas de hombre de letras: nos referimos a su labor como antólogo, 
es decir, de persona que a partir de su pericia de lector y de su gran conocimiento de un autor, un género literario, de un grupo generacional, de un tema común o de una etapa de la literatura realiza una tarea de selección de textos de cualquiera de estos tópicos y los ofrece a los lectores con un prólogo, un estudio y unas notas útiles para que el volumen sea mejor apreciado y sirva con más provecho a los interesados (historiadores, críticos literarios, científicos sociales, profesores, estudiantes y lectores en general).

En este terreno tan útil para elevar nuestro nivel individual y colectivo como lectores, Zavaleta nos ha obsequiado, por ejemplo, una magnífica y completa antología llamada Narradores peruanos de los 50'. Estudio y antología (2006). El valor de este volumen se acrecienta porque el antólogo es protagonista de esta generación y por tanto conoce a fondo el origen, la producción y las características de sus compañeros de aventura creativa, todos ellos gente de notable calidad. Otra hermosa y encomiable antología es: Cervantes en el Perú (2009), editada por la biblioteca nacional y en la que el ilustre compilador ha reunido, para gozo de los admiradores del máximo escritor de las letras castellanas, el famoso Manco de Lepanto, casi 40 textos (cuentos, ensayos, teatro, poemas en prosa) escritos por otros tantos autores peruanos dedicados al análisis y comentario de la inmortal novela El Quijote o a alguna otra obra del príncipe de nuestras letras. Entre los antologados figuran eruditos, psiquiatras, historiadores, ensayistas, poetas, novelistas, antropólogos, narradores del más alto nivel, y en cuyas páginas el lector encontrará luminosas palabras acerca del español más universal de todos los tiempos. Y a esta lista incompleta añadimos un par de compilaciones hechas por el autor sobre su vida y su obra: Antología personal (2009) y Cuentos para Caraz (2010).

Recibió muchos galardones y premios nacionales e internacionales a lo largo de su existencia, pero supo mantener la sencillez y la amabilidad en el trato con todos quienes se acercaban para dialogar con este peruano nacional y universal. Entre esos reconocimientos figura, sin duda, su incorporación, como miembro de número de la Academia Peruana de la Lengua. 